\section{El imperio de la imagen}

\author{
Andrés Valdez Zepeda
}

\section{Introducción}

E n los últimos años hemos observa— do una mayor preponderancia e influencia de la imagen en la política, que se ha convertido en una ventaja competitiva en la lucha por alcanzar o conservar espacios de poder público. Sin embargo, desde la época de los romanos, ya se le daba importancia a la iconografía de los políticos. Durante el imperio romano los gobernantes utilizaron las monedas para difundir la imagen pública del Estado romano bajo la protección de sus dioses. A lo largo del siglo II a.C., la imagen en las monedas se diversificó haciendo referencia a las gestas y a las divinidades protectoras de las familias de la nobleza que controlaban el poder. A partir del año 44 a.C., bajo el gobierno de Julio César, se incluyó la figura de los gobernantes en las monedas, después se amplió a la familia de los emperadores. $^{1}$

En el siglo XVI, Nicolás Maquiavelo ya señalaba la importancia de la reputación del gobernante y del cuidado de su apariencia, así como de las formas que se deberían seguir en la política. Por ejemplo, en El Príncipe, escrita en 1513, señalaba que "no es preciso que un príncipe posea todas las virtudes citadas, pero es indispensable que apa-

1 Fue Julio César quien dijo: "La mujer del César no solo debe ser honesta, sino también parecerlo". 
rente poseerlas", recomendando a los gobernantes que busquen "no ser odiados por el pueblo." Más adelante agrega: “... está bien mostrarse piadoso, fiel, humano, recto y religioso". Finalmente apunta: “... los hombres, en general, juzgan más con los ojos que con las manos, porque todos pueden ver, pero pocos tocar. Todos ven lo que pareces ser, mas pocos saben lo que eres".2

En México, desde el inicio de la Revolución Mexicana, Pancho Villa sabía de la importancia de la imagen. En 1911 rubricó con la Mutual Films Corporation un contrato para filmar la revolución tratando, por un lado, de obtener fondos económicos para financiar su movimiento y, por otro, cambiar con las filmaciones la imagen y percepción que el presidente Wilson y los americanos tenían del movimiento rebelde.

Hoy la imagen ocupa un lugar preponderante en las diferentes áreas del desarrollo de América Latina, convirtiéndose, además, en un campo laboral en expansión, ya que la imagen, el bienestar y el estilo de vida han generado, en el orbe, una industria de 200 mil millones de dólares anuales. ${ }^{3}$ En el campo de la política, bajo los nuevos sistemas electorales competitivos en la región, la imagen juega un papel muy importante para el éxito y la construcción de legitimidad social, ya que está asociada a la credibilidad, la confianza y la reputación de los actores e instituciones políticas.

Pero, ¿por qué la imagen se ha convertido en un factor preponderante en la política de América Latina que hace que muchos individuos asocien su futuro político a la construcción de percepciones sociales positivas?, ¿cuáles son las transformaciones que se han presentado en la región en los últimos años que hacen de la imagen un recurso estratégico para el desarrollo político?, ¿qué importancia tendrá la imagen en el futuro político de la región? En el presente escrito trataré de dar respuestas a estas interrogantes.

\section{Los factores que han incidido}

La preponderancia de la imagen en el campo de la política responde a una serie de factores y acontecimientos que se han presentado en los últimos años en América Latina y que han generado transformaciones en la forma de entender, procesar y hacer política. Los principales factores y acontecimientos que han propiciado el crecimiento de la preeminencia de la imagen son los cambios en el sistema político de la región, las nuevas tendencias

2 Véase MaQuiaVELO, Nicolás. El Príncipe. México: Editorial Siglo XXI, 1989.

3 ROSA, Alejandro de la. Milenio. México, 8 de febrero del 2005, p. 29. 
neogerenciales en el área pública, la crisis de las ideologías, el creciente desarrollo tecnológico, la crisis de la cultura de la palabra, el predominio de la cultura visual, la construcción de una nueva ciudadanía y, en general, por la nueva forma de hacer y entender la política.

Cada uno de estos factores está incidiendo de manera diferenciada para que la imagen sea una variable preponderante no solo para la clase política, sino también para determinar las decisiones y fijar preferencias y apoyos de la ciudadanía. Esto quiere decir que la imagen se ha convertido en una ventaja competitiva muy importante en la arena política, de tal forma que el éxito o fracaso en la competencia puede determinarse por las percepciones y el modelo de gestión de imagen que se impulse. De hecho, la política se ha convertido en una especie de batalla por las percepciones de la ciudadanía, en la que la imagen juega un papel de influencia y seducción decisivo.

\section{Democratización}

Una de las transformaciones más importantes que se han presentado en América Latina en los últimos años es el cambio del tipo de sistema político preponderante, lo que transformó también las formas de valoración, organización y decisión en la política. Esto es que la región experimentó una transición de regímenes autoritarios o semi- autoritarios hacia sistemas políticos democráticos, sustentados en la construcción de consensos sociales y la gestión de los afectos de los ciudadanos por parte de candidatos, partidos y gobernantes, todo dentro de un marco de libertad, pluralidad y competencia.

Bajo regímenes autoritarios o totalitarios, basados en la coacción, la violencia y el control social, no en la libertad, la imagen de los políticos y su valoración social resultaban irrelevantes. Es decir, bajo estos sistemas predemocráticos la opinión y percepción de los individuos y las masas acerca de la clase política no eran un factor relevante para el acceso y conservación del poder político, ya que las decisiones sobre el carácter de la representación pública y la legitimación social no dependían del apoyo popular. No es, sino hasta el inicio del proceso de transición hacia la democracia en la región, cuando la opinión de la gente y la valoración social sobre la imagen y la reputación de los políticos empiezan a cobrar importancia.

En el momento en que el voto popular y el respaldo de los ciudadanos se convierten en el mecanismo legítimo y hegemónico, que permite el ascenso y conservación del poder público, las características, acciones y actitudes de los políticos, así como la reputación, personalidad e imagen que proyectan empiezan a cobrar relevancia. De esta forma, la percepción social, representación, modelización o 
idealización de la realidad política por parte de los ciudadanos se convierte en una variable que activa actitudes y acciones de la clase política en la búsqueda de construcción de consensos sociales y ventajas políticas.

En ese momento, la imagen personal, así como la reputación pública de los políticos se convierte en una ventaja o desventaja competitiva sobre la que se sustenta parte del éxito y el futuro de la clase política. Es decir, la democracia, como sistema político basado en el consentimiento de los ciudadanos y en la correcta gestión de sus afectos, trajeron como consecuencia la valoración de la imagen como variable determinante del éxito político. Bajo otros sistemas predemocráticos, la imagen y los símbolos se utilizaron no para construir consensos sociales, sino para controlar y enajenar a las masas.

En suma, la preponderancia de la imagen en la política es consecuencia de la misma democracia, que implica un sistema de pluralidad y competencia política civilizada. Bajo este sistema, gestionar adecuadamente la imagen de los personajes y de las instituciones políticas se convierte en una ventaja competitiva y en un factor importante para acceder o conservar el poder.

\section{Neogerencia}

Otro de los cambios que se han presentado en América Latina en los últimos años es una nueva tendencia neo- gerencial, consistente en incorporar procesos, prácticas, métodos, sistemas y procedimientos que han surgido y se han desarrollado en el sector privado (empresa), pero que hoy día se aplican, utilizan e impulsan en el sector público. El propósito central de esta nueva tendencia es mejorar la gestión y uso de los recursos públicos, así como el construir una mayor legitimidad social, mediante acciones que permitan que los procesos sean más eficientes. De esta forma, encontramos por ejemplo en el sector público, la aplicación de los constructos de planeación estratégica, calidad total, reingeniería, mercadotecnia, benchmarking, administración por resultados y bursatilización de las finanzas, entre otros, incorporados con el objetivo de mejorar los procesos y hacer eficiente el uso de los recursos en el espacio público tanto local como nacional.

Esta nueva tendencia neogerencial ha originado la apertura necesaria en el área pública para que nuevas formas de hacer, entender y procesar la política se incorporen como prácticas que se consideran ventajosas para alcanzar los objetivos organizacionales. De esta forma, toma relevancia la imagen como constructo y referente estratégico de la política, bajo el nuevo sistema democrático, sustentado en la competencia y la nueva pluralidad en la región.

Esta nueva tendencia neogerencial posibilitó la incorporación de muchos 
de los conceptos, estrategias, técnicas y saberes que se usan en la empresa privada, específicamente en materia de imagen corporativa, primero, al sector público y, después, a la política. Es decir, la preponderancia de la imagen en la política tiene sus antecedentes en la empresa en forma de imagen corporativa de las organizaciones.

En la empresa, la imagen corporativa se utiliza como un referente estratégico imprescindible para lograr mayor visibilidad, confianza, credibilidad, posicionamiento y, sobre todo, una mayor competitividad en el mercado, de tal forma que el éxito o fracaso de las empresas depende, en gran medida, de la gestión de la imagen y la reputación de marca que sepan construir.

Debido a que el sector público de América Latina es muy proclive a impulsar la aplicación indistinta de diferentes procesos gerenciales que han sido útiles y beneficiosos para las organizaciones, la incorporación de la imagen como referente vital en la política no ha tenido mayores dificultades, aunque sí algunas críticas. ${ }^{4}$ De esta forma, en el espacio público, la imagen no solo se ha convertido en una obsesión de muchos políticos, sino que incluso, se está incorporando como referente estratégico importante en las instituciones públicas y en las organizaciones políticas y sociales, en la búsqueda de su desarrollo y consolidación.

\section{Crisis de las ideologías}

La imagen ha cobrado relevancia en la política, también, por la crisis en la que han caído los paradigmas ideológicos que fueron sustento, en cierta manera, de regímenes autoritarios o totalitarios. Ante el debilitamiento de las ideologías y el exacerbado pragmatismo predominante no solo en la clase política, sino también en gran parte de la ciudadanía, la imagen se ha convertido en un referente competitivo importante.

La teoría de los espacios públicos sustenta que todo vacío que se genera tiende a ser llenado u ocupado por alguien o algo, de tal forma que si las ideologías ya no son el referente que genere cohesión y seducción social, ahora la imagen, el carisma y la reputación de los actores políticos, como individuos, ocupan estos espacios y cumplen esas funciones. Es decir que la imagen del político se convierte en

4 Respecto de lo que señalan las críticas de la imagen y la preponderancia de la televisión, Mario Vargas Llosa expresa: "Me parece antimoderno, anacrónico, obsoleto, el rechazo de algo que hoy día forma parte de nuestra realidad de una manera irreversible; combatir la televisión, combatir los medios audiovisuales, me parece absurdo, como querer cambiar la ley de la gravedad, están ahí y ahí se van a quedar, y lo mejor que podemos hacer es sacarle el provecho que es posible sacarles" (Periódico Mural. Guadalajara, 30 de noviembre del 2005). 
el sustituto de las ideologías, para una sociedad ávida de referentes concretos y palpables, más que de credos ideológicos.

Los regímenes autoritarios y totalitarios utilizaban la ideología como un instrumento de control social, generando una especie de "hegemonía ideológica de Estado", en la que la pluralidad y la competencia de paradigmas políticos no estaba permitido. Bajo estos regímenes predemocráticos, la ideología permeó todas las acciones y tramas políticos del momento, como fue el caso, por ejemplo, de la ideología de la revolución mexicana, convirtiéndose en un aglutinador estratégico para la clase gobernante. Por su parte, la democracia permitió la convivencia de diferentes referentes ideológicos, lo que resultó en un debilitamiento de la ideología dominante. Es decir, el mismo sistema democrático generó condiciones de competencia que debilitó a las mismas ideologías como referentes políticos importantes para la clase política y la sociedad en su conjunto.

Esta crisis de las ideologías, que ha permitido que la imagen cobre mayor relevancia social, ha generado también el debilitamiento de las instituciones y organizaciones políticas, donde el individuo es más importante, cobrando una mayor notabilidad respecto de su organización o grupo. Es decir, la ima- gen del político se ha sobrepuesto a la imagen del grupo al que pertenece, e incluso, a la de la misma institución.

Daniel Innerarity señala que cuando las diferencias ideológicas se atenúan, las preferencias de los electores terminan fraguando por relación con la manera de hacer la política, cuya forma acaba siendo prioritaria frente a cualquier contenido. El aspecto más banalizante de esta transformación lo constituye la tendencia a formular sus elecciones a partir de criterios "estéticos" o cosméticos: la simpatía, la proximidad, incluso el modo de hablar o vestir. Es decir, en la dimensión de la representación, que tiene una importancia central en un momento en el que la política consiste fundamentalmente en escenificar y parecer. $^{5}$

Sin embargo, es importante precisar que no es que la imagen haya debilitado a las ideologías. Al contrario, ante la crisis de las ideologías, generada por un mayor pragmatismo de la sociedad y de la propia clase política, la imagen ha pasado a ocupar un espacio preponderante. De hecho, como se comentó anteriormente, la imagen siempre ha estado presente en la política, no es que recién se haya "usurpado" el lugar; simplemente hoy esta cobró mayor relevancia.

5 INNERARITY, Daniel. "Cuestión de estilo". El País, 29 de marzo del 2004. 


\section{Desarrollo tecnológico}

El desarrollo de la tecnología y su socialización han contribuido también al fortalecimiento de la imagen como nuevo paradigma sobre el que se sustenta la política contemporánea. La primacía de la televisión y su gran impacto en la sociedad, así como el desarrollo de las nuevas tecnologías de la información, como la internet, han transformado la forma tradicional de hacer y entender la política. De hecho, hoy día la política se hace preferentemente de forma mediática, de tal manera que si algo no está en los medios, principalmente en la televisión, entonces no existe, utilizándose la imagen no solo dentro de la estrategia política para ganar elecciones y gobernar, sino también para destruir adversarios, como es el caso de los videoescándalos. ${ }^{6}$

De esta forma, la tecnología ha posibilitado que la imagen se convierta en un referente estratégico importante, cuyo poder de persuasión sobre las masas se ha incrementado notablemente. ${ }^{7}$ De ahí que la clase política vea la imagen como un medio y un referente valioso para alcanzar sus fines y así lograr conseguir o conservar posiciones de poder.
Al respecto, Balandier apunta que el poder se legitima por la producción de imágenes, por la manipulación de símbolos y su organización en un espacio que podemos llamar la teatralidad estatal. ${ }^{8}$ En esta disputa del poder, los medios de comunicación como la televisión y la internet, están jugando un papel protagónico. Esto es, la revolución en la informática y en las telecomunicaciones sustentadas en la imagen, así como el poder de influencia que estas generan entre los diferentes grupos sociales, han hecho de la imagen un nuevo referente de poder.

\section{Crisis de la cultura de la palabra}

Antaño, la radio jugó un papel preponderante en las estrategias de información y comunicación política. Hitler y muchos dictadores como Mussolini y Stalin, por ejemplo, utilizaron la radio y la palabra como medios para alcanzar sus aviesos propósitos. Paradójicamente, también fue la radio la que dio VOZ a grupos disidentes, que finalmente terminaron destruyendo a los regímenes predemocráticos.

De hecho, desde las primeras décadas hasta los años cincuenta del siglo pasado, la radio fue el medio por anto-

6 Véase LEVARIO TURCOTT, Marco. "El imperio de la imagen" [en línea]. Etcétera. <http//www.etcetera. com.mx>.

7 MCLUHAN, Marshall. Understanding media. Nueva York: McGraw-Hill, 1964.

8 Citado por JIMÉNEZ, Edgar et al. Las decisiones políticas: De la planeación a la acción. México: Siglo XXI Editores/IFE, 2001. 
nomasia de la política de masas, siendo sustituido por la televisión a partir de la década de 1960. De esta forma, la cultura de la palabra empieza a ceder paso a la cultura visual, para consolidarse como un paradigma hegemónico a partir de las últimas décadas del siglo XX.

Esto no significa que la palabra deje de utilizarse hoy como medio de la política o que la cultura escrita haya desaparecido por completo como instrumento de comunicación y persuasión, sino únicamente que la imagen se ha sobrepuesto a las otras tanto en importancia como en poder de influencia.

Esta crisis de la cultura de la palabra ha generado un cambio en el perfil del político que la sociedad privilegia y apoya actualmente. En el pasado, eran los grandes oradores, los maestros de la palabra y la tribuna los que se imponían y triunfaban en la política. Estos grandes tribunos, con su elocuencia y su magistral dicción, lograban persuadir y movilizar a las masas. Hoy día, las cosas son diferentes. Los políticos fotogénicos e histriónicos, los que se han preocupado por construir y conservar una buena imagen integral, son los que se están imponiendo, debido a que la cercanía afectiva del político con la gente por medios televisivos es más efectiva. La oratoria está supeditada a la imagen, y los transistores dejan su lugar al plasma y a las nuevas tecnologías digitales.
Hoy más que nunca, la imagen de las personas es más fuerte que los símbolos y las palabras. Tanto la hoz y el martillo o el puño y la rosa como los discursos elocuentes han pasado a la historia, perteneciendo a una simbología del poder y una práctica política lejana, oscurecidas por la imagen de los líderes y las personalidades.

La importancia de la imagen y su preponderancia sobre la política se debe al hecho, también, de que las imágenes persuaden, teniendo un alto poder seductivo, mientras que las palabras comunican, y la lucha de hoy más que por comunicación es por persuadir y seducir a los diferentes públicos. Recuérdese que el papel de la imagen es mostrar, nunca decir.

El predominio de la cultura visual ha generado también ciudadanos más influenciables por los medios audiovisuales, quienes se informan de política principalmente a través de la televisión. De hecho, la televisión se ha constituido como instrumento efectivo y dominante de socialización e influencia política, que genera efectos persuasivos e identidades políticas. La televisión logra modificar la forma en la que los individuos conocen y comprenden la realidad que los rodea. Construyen imagen, pero también destruyen.

Giddens señala que los viejos mecanismos del poder no funcionan en una sociedad en la que los ciudadanos viven en el mismo entorno informativo 
que aquellos que los gobiernan. De esta forma, la televisión influye determinantemente en las percepciones que la gente tiene de la política y los políticos.

La televisión le ha dado protagonismo a las personalidades y a los liderazgos individualizados, debilitando las instituciones partidistas, de tal forma que en la actualidad muchos partidos dependen de personajes y líderes carismáticos.

Esta crisis de los partidos políticos ha hecho posible que la imagen de los hombres fuertes se imponga por encima de las instituciones. Para bien o para mal, la política se hace, hoy día, por formatos mediáticos, donde la imagen lo es prácticamente todo, en un mundo donde la política ha entrado en una nueva tendencia en la que se impone lo simbólico-afectivo como determinante del éxito.

\section{Cambios en la ciudadanía}

En los últimos años se han producido también cambios en la ciudadanía. Hoy se ejerce un tipo de ciudadanía más light y más superficial, en la que la mayoría de los ciudadanos no están interesados en la política ni se involucran en actividades de su comunidad. De hecho, estamos viviendo una época en la que predomina una ciudadanía despolitizada o incluso antipolitiza$\mathrm{da}$, que privilegia lo individual por encima de lo colectivo, la forma por encima del contenido.
En este tipo de sociedad, la imagen se convierte en un medio que moviliza sus sentimientos y emociones, generando incentivos para que la clase política trate de persuadirlos a través de estrategias mediáticas. Esto es, los cambios en la sociedad y las nuevas formas de ejercer la ciudadanía han generado incentivos para que la imagen se imponga como el paradigma predominante en el gusto de la gente, ante la existencia de un ciudadano de la contemplación convertido solo en espectador.

Antaño, la política tenía, además, un carácter más profundo, en el que el fondo tenía más importancia que la forma. Hoy día, el fondo no importa tanto. Lo que importa más es el ser entretenido, el caer bien, el agradar y el ganar el afecto de la gente, lo cual se logra mejor a través de la manipulación inteligente de imágenes y símbolos. Quitar profundidad, argumento y densidad para ganar en estética, afecto e impacto en los públicos.

La naturaleza del ser humano y sus canales rectores de comunicación y percepción influyen para el predominio de la imagen por encima de la palabra. De hecho, de acuerdo con diferentes investigaciones que se han realizado, se ha concluido que el 83 por ciento de las decisiones del ser humano las hace por la información que le es suministrada a través de la vista. Al respecto, existen diversos adagios populares que enfatizan sobre la importancia de la vista sobre los otros senti- 
dos. Por ejemplo, el dicho "ver para creer" establece que el ser humano supedita su credibilidad solamente a lo que es visto. Es decir, a la imagen.

Por su parte, los proverbios populares "de la vista nace el amor" y "el primer paso para ser es parecer," apuntan a que el gusto y la percepción de la gente está antecedida de la imagen. Al respecto, se puede decir que el hombre que ve parece tener mayor importancia que el hombre que lee. Sin embargo, al contrario de lo que dice Sartori (2003), la imagen no es enemiga de la inteligencia, de la profundidad del sentido ni de la intensidad sensorial. 9 La imagen solo es un medio, nunca un fin.

En suma, los ciudadanos están más interesados en el entretenimiento que en la educación política. Les importa más divertirse, privilegiando, por ejemplo, una programación televisiva centrada en el entretenimiento y la vacuidad.

\section{A manera de conclusión}

La imagen constituye un elemento preponderante más de la política moderna, en la medida en que la política se ha convertido en un asunto de percepciones. Hoy no se puede hacer políti- ca y ser exitoso sin acudir a las estratagemas de la imagen, ya que en la batalla por ganar la ilusión pública y el poder político, la imagen y la percepción de los públicos lo es prácticamente todo, debido al hecho de que la política es también, y ante todo, una imagen.

En América Latina, la imagen se ha convertido en un factor preponderante en la política, debido a las grandes transformaciones políticas, sociales y culturales que se realizaron en los últimos años en la región. Estas transformaciones han afectado la forma tradicional de hacer, entender y procesar la política en la región.

Asimismo, la imagen es la percepción que los públicos tienen sobre una determinada realidad o acción. En política la percepción es la realidad. En este sentido, no es exagerado decir que gobernar es parecer. No es lo que es, sino lo que se percibe, lo que parece. De hecho, en una sociedad democrática, como la que se está construyendo en América Latina, la lucha por el poder político es la lucha por ganar las percepciones de los públicos y por conquistar los corazones y el afecto de la gente.

La imagen es una relación entre sujetos y grupos sociales que se ha convertido en un elemento determinante

9 SARTORI, Giovanni. Video-politica. Medios, información y democracia de sondeo. México: Fondo de Cultura Económica, 2003. 
de las relaciones de poder, que se encuentra sujeta a múltiples mediaciones. Quien tiene una mejor imagen o sabe gestionarla adecuadamente, tiene una gran ventaja competitiva. Ya sea como factor de influencia, como instrumento de liderazgo o como referente estratégico, la imagen se ha impuesto como el paradigma predominante de la política en la era moderna.
Imagen y poder son dos constructos interrelacionados. Parafraseando a Orwell, cuando anotaba que quien controlaba el pasado controlaba el presente, hoy podemos decir que quien controla la imagen controla el poder del presente y del futuro. Es decir, en el futuro la imagen será una variable determinante en la política. 